\title{
Medical Education Centre for Research, Innovation and Training (MECRIT)
}

\author{
Tashi Norbu ${ }^{1}$
}

${ }^{1}$ Medical Education Centre of Research \& Innovation Training, Khesar Gyaplo University of Medical Sciences of Bhutan, Thimphu, Bhutan

The Khesar Gyalpo University of Medical Sciences of Bhutan is the only medical university in Bhutan with affiliations and collaborations with various renowned international universities. The University aims to become one of the premier centers for academics and research. Therefore, the stature of the university should enable to attract the investment and also ensure the quality of activities carried out. The University has full time and designated faculty members in wide array of medical and health field's expertise, who would implement the activities professionally.

The Ministry of Health, Drug Regulatory, Bhutan Narcotics Agency and others carry out numerous training, research and seminars, often without clear modules and learning objectives, compromising on the quality and professionalism. These activities if given opportunity can be delivered by the University in a coordinated and professional manner by a team of qualified faculty members. This will also be in line with the Bhutan Health and Medical Council which mandates the requirement of continual medical education for all health workers to fulfill their membership requirements.

Additionally, there is growing demand from the private agencies and individuals for short course in various health and medical fields which can be coordinated and conducted by the University. The University could attract various international grants, activities to conduct seminars, workshops and training in the country besides attract various scholar to do their $\mathrm{PhD}$ and other research activities in Bhutan.

The MECRIT would cater but not limited to Continual Medial Education, Continual Professional Development, Research Grants, Consultancy services by the University and faculty members, Ph.D. scholars to conduct research at the University, Attract Foreign Scholars to conduct research, Faculty members to provide talks and expert services and Organize seminars/workshops and conferences.

The main aim of the MECRIT is for the growth of the overall University along with respective faculty development. It will be a leading Center for Continual Professional Development, and Research and Innovation in Bhutan

The MECRIT will have following major roles and responsibilities but not limited to:

- Coordinate, organize and conduct CME and CPD for the clients

Corresponding author:

Tashi Norbu

tashinorbu797@gmail.com
- Coordinate and provide consultancy services in various health and medical related fields;

- Develop and registry for the expertise both within the outside the university

- Co-ordinate both from within and outside the University for research grants and consultancy services and applications

- Develop training modules and training activities

- Develop marketing strategies and conduct marketing for the services of MECRIT and the University

- Publish Bhutan Medical Journal and other publications of MECRIT and for University

- Mobilization of teaching-learning materials and other logistics;

- Mobilize funding support, such as research grants, scholarships, etc., from individuals and institutions;

- Bring about innovations in medical education, training methods, healthcare delivery system, etc.

- Innovate on instructional materials to support teaching and learning process.

- Revenue generation for UMSB and its constituents;

- Another responsibilities assigned by the Board or the President

The cornerstone of any organization is its human resource. In order to maintain, upgrade and retain this essential commodity, continuing education is one of the areas identified and invested by the organizations. To this end, many organizations within the country send their employees outside to refresh, update and train them to deliver better results. Recognizing the inevitability and the importance of continuing education in motivating and development of human resource in every organization and also considering the paucity of institutions catering to such demands within the country, the university, under MECRIT has established the Continuing Education (CE) unit to tap in the growing demand and develop relevant and cost-effective courses, which are outside the regular long-term courses offered by the university. Besides being a solution to address the human resource development need of the different organizations, continuing education unit is also one of the means to generate additional income for the university in line with the Tertiary Education Policy of the kingdom of Bhutan 2010, which anticipates universities to raise fund from different sources.

The goal of the continuing education is to improve and enhance individual, group and organizational effectiveness through professional development by providing quality and cost effective programs and also serve as an alternative source of income for the university. 
The programs offered under continuing education unit are based on the increasing demand from the external agencies within the country as well as international agencies and universities across the globe. These programs are outside the regular courses offered by different faculties and are intended for continual professional development or for general education purposes and do not, in themselves lead to award of university. It consists of Scheduled, Project tied and Tailor-made programs depending on the demand of clients. The areas of training will be mainly based on health.

The quality, standard and the relevance of the programs under continuing education unit are ensured to meet the expectations of the clients. To this end all the courses will be subjected to external quality assurance system as well as internal quality control mechanisms.

All the courses offered under continuing education unit are subject to validation by a separate entity or a committee of experts and periodic evaluation and review carried out for improvement. This is mainly to ensure that the quality, standards and relevance of the courses fulfill the goal of CE. The programs under $\mathrm{CE}$ unit fall within the ambit of Bhutan Medical and Health Council (BMHC). Therefore, the CE Unit as well as the programs offered are accredited by BMHC in order to ensure the quality of the courses, assign credits and also to gain recognition from the clients.

The CE unit shall conduct client satisfaction surveys periodically to measure its performance for improvement and shall also participate in externally run surveys. The programs shall be conducted only by qualified facilitators and resource persons.

CE unit under MECRIT shall be responsible for coordinating all matters related to administration of course including marketing. All business linked with courses shall be routed through MECRIT. No direct arrangement shall be made between the provider of course and the clients. 